\title{
An interesting cross-talk between the glucagon-like peptide-1 receptor axis and angiotensin receptor pathway for modulation of renal sodium handling in obesity
}

\author{
Kouichi Tamura ${ }^{1}$ Takahiro Yamaji ${ }^{1} \cdot$ Takayuki Yamada $^{1} \cdot$ Masato Ohsawa $^{1} \cdot$ Hiromichi Wakui $^{1}$
}

Received: 2 July 2018 / Accepted: 5 July 2018 / Published online: 15 August 2018

(c) The Japanese Society of Hypertension 2018

The number of patients with obesity-related disease is increasing, and obesity is a major medical problem associated with the development of hypertension, type 2 diabetes (T2DM), dyslipidemia, and ultimately life-threatening cardiovascular disease (CVD) [1]. Obesity is reportedly often accompanied by hypertension, and obesity-related hypertension is closely associated with the development of systemic atherosclerosis along with T2DM and dyslipidemia, resulting in increased CVD morbidity [2]. Therefore, there is a need for new treatment strategies for the management of both obesity and hypertension [3, 4]. It is also reportedly shown that patients with T2DM are increasing in number, and renal and cardiovascular complications often provoke serious conditions in diabetic patients [5]. Cardiovascular complications are the main cause of death in diabetic patients with nephropathy, and major risk factors for CVD in these patients include hypertension, dyslipidemia, albuminuria (proteinuria), and a decreased glomerular filtration rate (GFR) [6-9].

Diabetic patients are encouraged to strictly control their blood glucose levels, as well as their blood pressure (BP) levels. Recently developed drugs, such as glucagon-like peptide (GLP)-1 receptor agonists, dipeptidyl peptidase (DPP)-4 inhibitors and sodium glucose cotransporter-2 (SGLT2) inhibitors, also have hypotensive actions, making them ideal for use in diabetic patients with hypertension [10]. The results of large-scale clinical studies showed that treatment with SGLT2 inhibitors significantly reduced the occurrence of the primary composite cardiovascular

Kouichi Tamura

tamukou@med.yokohama-cu.ac.jp

1 Department of Medical Science and Cardiorenal Medicine, Yokohama City University Graduate School of Medicine, Yokohama, Japan outcome in T2DM patients [11, 12], at least partly via beneficial BP reduction by the SGLT2 inhibitor [13]. A previous study examined a direct relationship between the therapeutic effects of an SGLT2 inhibitor and an alteration in circadian BP rhythm in salt-loaded obese Otsuka LongEvans Tokushima Fatty (OLETF) rats, a rat model of T2DM, and showed that the SGLT2 inhibitor ameliorated the salt loading-mediated BP elevation with normalization of altered diurnal BP variation to a dipper profile, which was associated with an increase in urinary sodium excretion and a tendency toward a reduction in albuminuria [14].

GLP-1 is a gut incretin hormone that is considered a promising therapeutic agent for T2DM because it stimulates beta cell proliferation and insulin secretion in a glucosedependent manner. Although GLP-1 therapeutic use is limited by its rapid inactivation by the DPP- 4 enzyme that results in a short plasma half-life, the use of GLP-1 receptor agonists, GLP-1 analogs that are resistant to DPP-4 inactivation and DPP-4 inhibitory agents were developed to resolve these limitations [15].

The results of large-scale clinical studies show that treatment with GLP-1 analogues significantly reduces the occurrence of the primary composite cardiovascular outcome in T2DM patients $[16,17]$. In addition, concerning the effects of GLP-1 in the kidney, cumulative evidence supports a role for GLP-1 in modulating renal function, and several previous studies show that GLP-1 is a physiologically relevant natriuretic factor that contributes to sodium balance, in part via tonic modulation of $\mathrm{Na}+/ \mathrm{H}+$ exchanger isotope 3 (NHE3) activity in the renal proximal tubules; however, the mechanisms by which GLP-1 induces diuresis and natriuresis have not been completely established [15, 18-20].

Interestingly, in this issue, Rodriguez et al examined the effects of a GLP-1 receptor agonist, exenatide, in combination with AT1 receptor blockade by olmesartan, an ARB, on urinary sodium excretion and elevated BP in diabetic 
Fig. 1 A schematic representation of the dual promotion of natriuresis by a combination of GLP-1-GLP-1 receptor activation and Ang IIAT1 receptor inhibition in the renal proximal tubule in obesity

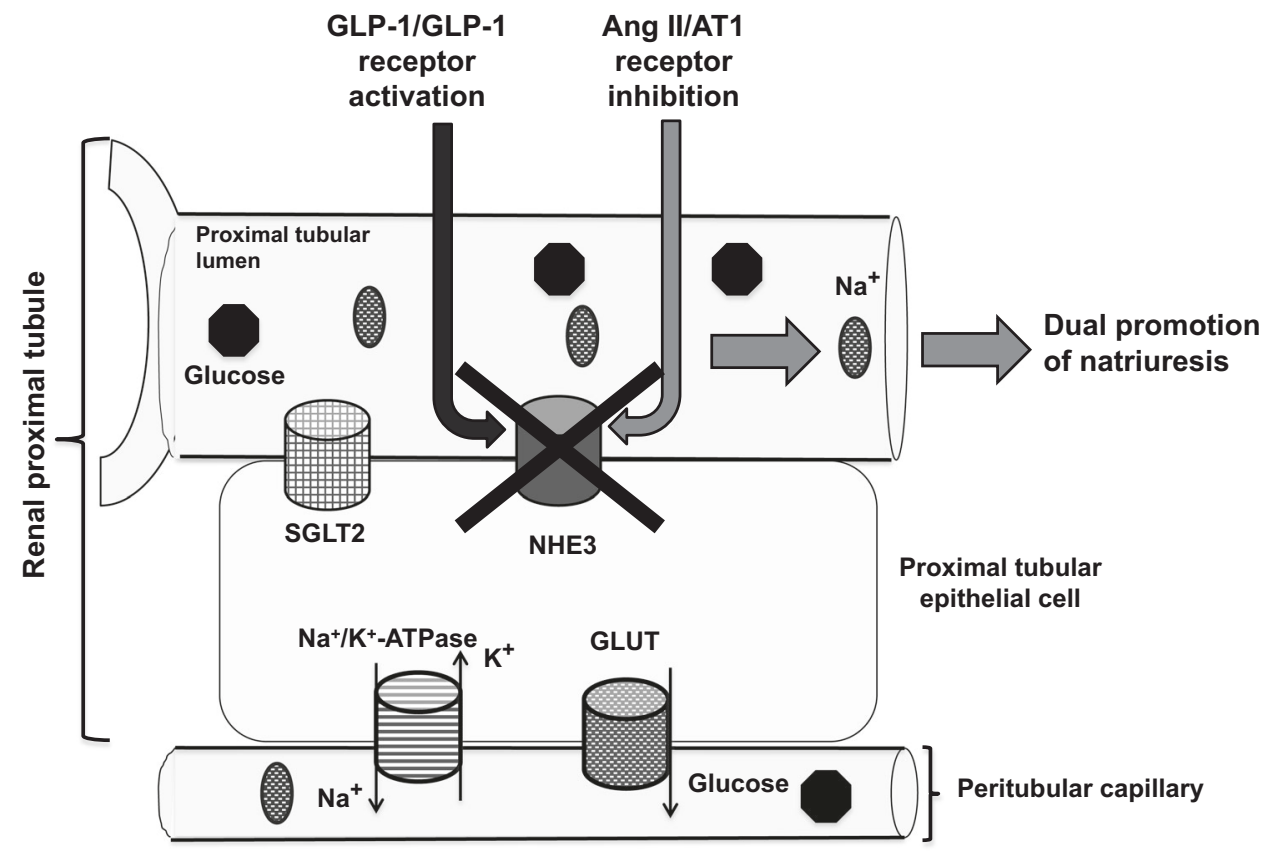

OLETF rats [21]. The authors showed that the GLP-1 receptor agonist in combination with the ARB significantly increased urinary sodium excretion but did not lead to a further BP decrease, probably due to the compensatory HR increases that occurred in the OLETF rats. The experiments are well performed, and the results are interesting and important for understanding the pathophysiology of hypertension and the functional importance of GLP-1 receptor activation in $\mathrm{T} 2 \mathrm{DM}$. The results of this basic study, which used an animal model of obesity hypertension, were also consistent with the results of a previous systematic review and network meta-analysis that examined the impact of GLP-1 receptor agonists on BP, heart rate and hypertension among T2DM patients [22]. In the systematic review and network meta-analysis, treatment with GLP-1 agonists was associated with modest BP reduction and a slight increase in heart rate, yet no significant association with hypertension was found [22].

Furthermore, previous studies showed that the renal renin-angiotensin system plays a critical role in renal sodium handling and BP regulation in pathophysiology [23]. Therefore, possible effects of GLP-1 agonists on the renal renin-angiotensin system, such as urinary angiotensinogen excretion and possible crosstalk(s) between the renal GLP-1 axis and renal renin-angiotensin system in the modulation of renal sodium handling and BP regulation, would be very interesting. The effects of activation of the renin-angiotensin system via the binding of Ang II to AT1 receptors on NHE3 in the renal proximal tubules have been extensively studied, and several studies have identified a number of signal transduction pathways involved in NHE3 activation. The stimuli or conditions that cause upregulation of NHE3 include Ang II-AT1 receptor signaling and the sympathetic nervous system, whereas the GLP-1-GLP-1 receptor axis acts by inhibiting the NHE3-mediated $\mathrm{Na}$ $+/ \mathrm{H}+$ exchange $[24,25]$. Therefore, the renal proximal tubule may be a possible target of interest for the functional cross-talk between Ang II-AT1 receptor signaling and the GLP-1-receptor axis in the modulation of renal sodium handling and regulation of BP in obesity-related hypertension, and further experiments and clinical evidence are necessary to seek the answer (Fig. 1).

Acknowledgements The authors were supported by grants from a Uehara Memorial Foundation grant, Grants-in-Aid for Scientific Research from the Japan Society for the Promotion of Science, grants rom SENSHIN Medical Research, the Banyu Life Science Foundation International and the Salt Science Research Foundation (18C4), and a grant-in-aid from The Cardiovascular Research Fund, Tokyo, Japan. The authors are also supported by the grant of Strategic Research Project of Yokohama City University, Japan Agency for Medical Research and Development (AMED) and by The Translational Research program; Strategic PRomotion for practical application of INnovative medical Technology (TR-SPRINT) from AMED.

Funding K.T. received research grants from Takeda, Daiichi Sankyo, Pfizer, Astellas, MSD, Mochida, Teijin Pharma and Nippon Boehringer Ingelheim and honoraria from Nippon Boehringer Ingelheim, Daiichi Sankyo, Dainippon-Sumitomo and Mochida.

\section{Compliance with ethical standards}

Conflict of interest Concerning the disclosure information, K.T. received research grants from Takeda, Daiichi Sankyo, Pfizer, Astellas, MSD, Mochida, Teijin Pharma and Nippon Boehringer Ingelheim, and honoraria from Nippon Boehringer Ingelheim, Daiichi Sankyo, Dainippon-Sumitomo and Mochida. 


\section{References}

1. Ng M, Fleming T, Robinson M, Thomson B, Graetz N, Margono $\mathrm{C}$, et al. Global, regional, and national prevalence of overweight and obesity in children and adults during 1980-2013: a systematic analysis for the Global Burden of Disease Study 2013. Lancet. 2014;384:766-81.

2. Landsberg L, Aronne LJ, Beilin LJ, Burke V, Igel LI, Lloyd-Jones $\mathrm{D}$, et al. Obesity-related hypertension: pathogenesis, cardiovascular risk, and treatment--a position paper of the The Obesity Society and The American Society of Hypertension. Obes (Silver). 2013;21:8-24.

3. Azushima K, Tamura K, Haku S, Wakui H, Kanaoka T, Ohsawa $\mathrm{M}$, et al. Effects of the oriental herbal medicine Bofu-tsusho-san in obesity hypertension: a multicenter, randomized, parallel-group controlled trial. Atherosclerosis. 2015;240:297-304.

4. Krzesinski P, Stanczyk A, Piotrowicz K, Gielerak G, UziebloZyczkowska B, Skrobowski A. Abdominal obesity and hypertension: a double burden to the heart. Hypertens Res. 2016;39:349-55.

5. Teramukai S, Okuda Y, Miyazaki S, Kawamori R, Shirayama M, Teramoto T. Dynamic prediction model and risk assessment chart for cardiovascular disease based on on-treatment blood pressure and baseline risk factors. Hypertens Res. 2016;39:113-8.

6. Adler AI, Stevens RJ, Manley SE, Bilous RW, Cull CA, Holman RR. Development and progression of nephropathy in type 2 diabetes: the United Kingdom Prospective Diabetes Study (UKPDS 64). Kidney Int. 2003;63:225-32.

7. Ninomiya T, Perkovic V, de Galan BE, Zoungas S, Pillai A, Jardine $\mathrm{M}$, et al. Albuminuria and kidney function independently predict cardiovascular and renal outcomes in diabetes. J Am Soc Nephrol. 2009;20:1813-21.

8. Drury PL, Ting R, Zannino D, Ehnholm C, Flack J, Whiting M, et al. Estimated glomerular filtration rate and albuminuria are independent predictors of cardiovascular events and death in type 2 diabetes mellitus: the Fenofibrate Intervention and Event Lowering in Diabetes (FIELD) study. Diabetologia. 2011;54:32-43.

9. Ohishi M. Hypertension with diabetes mellitus: physiology and pathology. Hypertens Res. 2018;41:389-93.

10. Katayama S, Hatano M, Issiki M. Clinical features and therapeutic perspectives on hypertension in diabetics. Hypertens Res. 2018;41:213-29.

11. Zinman B, Wanner C, Lachin JM, Fitchett D, Bluhmki E, Hantel $\mathrm{S}$, et al. Empagliflozin, cardiovascular Outcomes, and Mortality in Type 2 Diabetes. N Engl J Med. 2015;373:2117-28.

12. Neal B, Perkovic V, Mahaffey KW, de Zeeuw D, Fulcher G, Erondu N, Group CPC.. et al. Canagliflozin and Cardiovascular and Renal Events in Type 2 Diabetes. $N$ Engl J Med. 2017;377:644-57.

13. Rahman A, Hitomi H, Nishiyama A. Cardioprotective effects of SGLT2 inhibitors are possibly associated with normalization of the circadian rhythm of blood pressure. Hypertens Res. 2017;40:535-40.
14. Takeshige Y, Fujisawa Y, Rahman A, Kittikulsuth W, Nakano D, Mori $\mathrm{H}$, et al. A sodium-glucose co-transporter 2 inhibitor empagliflozin prevents abnormality of circadian rhythm of blood pressure in salt-treated obese rats. Hypertens Res. 2016;39:41522.

15. Crajoinas RO, Oricchio FT, Pessoa TD, Pacheco BP, Lessa LM, Malnic G, et al. Mechanisms mediating the diuretic and natriuretic actions of the incretin hormone glucagon-like peptide-1. Am J Physiol Ren Physiol. 2011;301:F355-63.

16. Marso SP, Bain SC, Consoli A, Eliaschewitz FG, Jodar E, Leiter LA, Investigators $S$ et al. Semaglutide and Cardiovascular Outcomes in Patients with Type 2 Diabetes. $\mathrm{N}$ Engl J Med. 2016;375:1834-44.

17. Marso SP, Daniels GH, Brown-Frandsen K, Kristensen P, Mann JF, Nauck MA, Investigators LT.. et al. Liraglutide and Cardiovascular Outcomes in Type 2 Diabetes. $\mathrm{N}$ Engl $\mathrm{J}$ Med. 2016;375:311-22.

18. Skov J. Effects of GLP-1 in the kidney. Rev Endocr Metab Disord. 2014;15:197-207.

19. Farah LX, Valentini V, Pessoa TD, Malnic G, McDonough AA, Girardi AC. The physiological role of glucagon-like peptide-1 in the regulation of renal function. Am J Physiol Ren Physiol. 2016;310:F123-27.

20. Savignano FA, Crajoinas RO, Pacheco BPM, Campos LCG, Shimizu MHM, Seguro AC, et al. Attenuated diuresis and natriuresis in response to glucagon-like peptide-1 in hypertensive rats are associated with lower expression of the glucagon-like peptide-1 receptor in the renal vasculature. Eur $\mathbf{J}$ Pharmacol. 2017;811:38-47.

21. Rodriguez R, Moreno M, Lee AY-P, Godoy-Lugo JA, Nakano D, Nishiyama A, et al. Simultaneous GLP-1 receptor activation and angiotensin receptor blockade increase natriuresis independent of altered arterial pressure in obese OLETF rats. Hypertens Res. 2018. https://doi.org/10.1038/s41440-018-0070-0 [Epub ahead of print].

22. Sun F, Wu S, Guo S, Yu K, Yang Z, Li L, et al. Impact of GLP-1 receptor agonists on blood pressure, heart rate and hypertension among patients with type 2 diabetes: A systematic review and network meta-analysis. Diabetes Res Clin Pract. 2015;110:26-37.

23. Kobori H, Nangaku M, Navar LG, Nishiyama A. The intrarenal renin-angiotensin system: from physiology to the pathobiology of hypertension and kidney disease. Pharmacol Rev. 2007;59:25187.

24. Pontes RB, Crajoinas RO, Nishi EE, Oliveira-Sales EB, Girardi AC, Campos RR, et al. Renal nerve stimulation leads to the activation of the $\mathrm{Na}+/ \mathrm{H}+$ exchanger isoform 3 via angiotensin II type I receptor. Am J Physiol Ren Physiol. 2015;308: F848-56.

25. Crajoinas RO, Polidoro JZ, Carneiro de Morais CP, CasteloBranco RC, Girardi AC. Angiotensin II counteracts the effects of cAMP/PKA on NHE3 activity and phosphorylation in proximal tubule cells. Am J Physiol Cell Physiol. 2016;311:C768-76. 